\title{
BMI1 Inhibitor PTC596
}

National Cancer Institute

\section{Source}

National Cancer Institute. BMI1 Inhibitor PT C596. NCI Thesaurus. Code C121645.

An orally active inhibitor of the polycomb ring finger oncogene BMI1 (B-cell-specific Moloney murine leukemia virus integ ration site 1), with potential antineoplastic activity. Upon oral administration, BMI1 inhibitor PT C596 targets BMI1 expressed by both tumor cells and cancer stem cells (CSCs), and induces hyper-phosphorylation of BMI1 leading to its degradation. This inhibits BMI1-mediated signal transduction pathways and results in a reduction of proliferation of BMI1-expressing tumor cells. BMI1, a key protein in the polycomb repressive complex 1 (PRC1), is overexpressed in certain tumor cell types, and plays a key role in CSC survival, proliferation and resistance to chemotherapeutics; its expression is associated with increased tumor aggressiveness and a poor prognosis. 